\title{
Beyond cybersafety: The need to develop social media literacies in pre-teens
}

\author{
Luci Pangrazio \\ luci.pangrazio@deakin.edu.au \\ Deakin University, Australia \\ Lourdes Cardozo Gaibisso \\ lourdes@uga.edu \\ Universidad ORT, Uruguay
}

\begin{abstract}
Cybersafety has been a mainstay of digital education since computers arrived in classrooms in the mid 1990s. Whether schools encourage students to be "cybersmart" (Australia), "netsafe" (New Zealand) or to be aware of "cybersecurity strategies" (Mexico and Chile) most now devote a relatively large amount of time and money to teaching young people how to "stay safe" online. In this article, we argue that it is time for schools to move beyond the cybersafety discourse to encourage students to think more critically about the digital media they use. Reporting on the digital practices of 276 pre-teens aged 7-12 years in Australia and Uruguay, we contend that the everyday digital challenges young people face are now beyond the scope of most cybersafety programs. Our findings highlight that many of the issues preteens are negotiating call for more nuanced and sustained educational programs that support the development of critical social media literacies. In particular, with the proliferation of mass user platforms and artificial intelligence, there is a need for schools to educate students around managing and protecting their personal data. The article concludes with a discussion of the digital learning required for young people in an increasingly datafied society.
\end{abstract}

\section{Keywords}

Pre-teens; digital practices; digital literacies; critical social media literacies, comparative research. 


\section{Introduction}

Children's use of the internet has grown in the last decade. In many parts of the world, homes are filled with digital technologies with many children having their first digital experiences in the earliest years of life. Indeed, the rise of tablets and touchscreens mean a range of digital experiences have become accessible to young children. The pre-teens or tweens (ages 7-12 years) of contemporary times are what Leathers, Summer and Desollar (2013) call "digitods" - children born after the introduction of the iPhone in 2007 - starting their lives with ready access to the internet. While this might mean more children can access digital technologies at younger ages, it does not mean they will use them effectively. The assumption that children across the world are equally empowered by digital technologies is highly problematic. For some time now, it has been recognised that making the most of digital experiences requires both access to digital technologies and effective use (Selwyn, 2004). Learning how to use digital media effectively should therefore be an important part of contemporary education.

While there is evidence of innovative digital programs taking place in flagship schools and research projects, the dominant form of school based digital learning today is cybersafety. As the name suggests, cybersafety focuses on keeping young people "safe" online and promotes a cautious approach to using the internet based around mitigating risk. Minimising digital "footprints", identifying risks and developing responses to socially challenging content and interactions are key to cybersafety (Roddel, 2006). While it is true that digital media introduces new forms of risk (Livingstone, 2009), it also provides a range of new opportunities. In fact, online risk and opportunity are often intertwined. For example, signing up to a new platform requires one to provide personal information online. Risk and opportunity are often thought to be mutually exclusive, however, when it comes to the digital context there is, in fact, a positive correlation between the two; the more risks one takes, the more opportunities they will encounter, and vice versa (Livingstone \& Helsper, 2010).

While cybersafety may draw young people's attention to the potential dangers of the internet, it has been critiqued for perpetuating conservative, risk averse practices that limit opportunities for digital learning and communication (Hope, 2013; Pangrazio, 2019). Indeed, cybersafety has little focus on developing digital resilience and agency (Third et al., 2014), critique (Emejulu \& Mc Gregor, 2019) and prosocial forms of participation - all skills which are considered important for success in a digital world. A key part of preparing young people for living and learning with digital media should therefore be developing the skills to critically analyse the risks and opportunities encountered in the digital context and navigating these with agency and autonomy. This is becoming increasingly important as "risks" are not only prevalent in content and interactions, but also in the very infrastructure of digital platforms.

In recent years a range of platforms have gained popularity due to being either automatically installed on devices (i.e. Messages on iPads) or discursively constructed as "educational" (i.e. Minecraft and Roblox), expanding the pathways into social media for young children. In addition, primary schools promote the use of mobile devices such as iPads, which can be used to access social media. Despite this, there is little empirical evidence investigating what pre-teens are actually doing online, and even less is known about their social media practices. This could be due to the fact that many of the mainstream platforms require a minimum age of 13 , which has prevented researchers from investigating their social media use.

This article presents a snapshot of social media practices of 276 pre-teens aged (7-12 years) in Australia and Uruguay. Despite obvious contextual differences between Australia and Uruguay, our findings highlight just how active and engaged pre-teens are with digital technologies, indicating engagement with a broad range of social media. We use the findings of our study to guide new

L. Pangrazio \& L Cardozo Gaibisso

Digital Education Review - Number 37, June 2020- http://greav.ub.edu/der/ 
approaches to digital learning that respond to the emergent challenges children and young people face in an increasingly datafied world.

\section{Why are pre-teens an important demographic for research on digital learning?}

"Pre-teen" students (aged 7-12 years) represent a growing demographic of social media users around the world. While marketers have adopted the term "tween" to represent the period "in-between" childhood and teen-hood, this age group represents more than just a chronological stage. As Brito (2012) explains it is also an important social and cultural category, representing a period of transition and ambiguity, particularly in regard to socio-psychological development. While pre-teens typically display characteristics of childhood, such as parental and emotional dependence, they are also developing a sense of autonomy and independence (Berger, 2014; Abiala \& Hernwall, 2013). In particular, social media provide a space in which their burgeoning independence and social relations with others can be experimented with. These practices are shaped by the sociocultural context in which they are enacted, meaning that this is far from a homogenous group (Livingstone, 2009).

Despite the fact that many social media platforms have a minimum user age of 13 years, there is evidence that children younger than this are opening social media accounts (Young, 2019). While children are often described as "youthful experts" or "pioneers" (Livingstone, 2009), there are several areas of social media use, such as privacy and self-representation, that are particularly challenging for pre-teens. These complex issues are overlooked by cybersafety education and provide the impetus for this research.

\section{Current research on pre-teens' digital literacies}

Although pre-teens are developing their understandings of digital technologies, these are far from consolidated. As Shin, Huh and Faber (2012) contend, pre-teens have a tendency to "overestimate their understanding and invulnerability and engage in risky behaviors" (p.644). Early Australian research into children's use of MySpace found younger children were more inclined to disclose personal information online (De Souza \& Dick, 2008). The researchers concluded that this was due to a limited awareness and understanding of the risks involved in social media practices. Indeed, younger children find it more difficult to conceptualise the interconnected nature of the internet, instead seeing their computer with few connections to other components (Denham, 1993). In a similar way, research by Yan (2005) found that due to their "limited understanding and limited direct online experience", children aged 5-8 years are "the most vulnerable online group" (p.394). Yan (2005) concluded that while 9-10 year olds are in a transitional stage of development, it is at this age that an educational component would be most beneficial to "educate these children about the technical and social complexity of the Internet and how to use the Internet safely and intelligently" (p.394).

While having a digital presence is now considered important to future prospects and social opportunities (Marwick, Fontaine \& boyd, 2017), the literature highlights that understanding and negotiating the issues associated with social media use are complex. Constructing a digital identity, maintaining privacy in networked contexts and understanding the implications of personal data all require digital maturity and fluency. As the most inexperienced users of social media, pre-teens require support to ensure that they might benefit from connectivity, without implications for their future or risking their digital rights. 


\section{Methodology}

\section{a. Research questions}

Our starting point for this research is that these complex negotiations are beyond the scope of many cybersafety programs. With these concerns in mind, we were interested in the digital experiences of pre-teens and the challenges that emerge as a consequence. This will enable us to consider how school based digital learning may be reimagined beyond cybersafety to support students to navigate these challenges with agency and autonomy. The research sought to address the following question:

1. What are typical digital practices for pre-teens in Australia and Uruguay and what challenges emerge as a consequence?

\section{b. Research setting and participants}

As a comparative study the research explored how different sociocultural contexts have shaped participant's digital practices, particularly their use of social media, and therefore contributes to an emerging trend in digital research that focuses on everyday appropriations of social media platforms (cf. Miller, 2016). The research took place in school settings in Australia and Uruguay.

The research was conducted in two primary schools (Surfcoast Primary School and Mountain View Primary School) in regional Victoria and involved 144 pre-teens (7-12 years) with roughly even numbers of boys and girls. In Uruguay, the research took place in two schools (Escuela Primaria A2 y Escuela Primaria B2), and involved 132 pre-teens (9-12 years), with similar characteristics to the Australian context. Escuela Primaria A2 is a traditional 4-hour a day school, while Escuela B2 is an extended time (7-hour a day school) one.

\section{c. Data collection and analysis}

To gather insights into the digital practices of pre-teens we required broad sweep data on a range of things, including; how and why they access the internet; whether they use social media, which platforms they use and how long they have had these for; and who they speak to if they are having issues with social media. To do this we used an online survey that included a range of multiple choice questions (see Appendix A for the online survey questions). Focus group interviews were also conducted with a random selection of participants. The focus group questions were designed to clarify particular areas of interest and/or add detail to the findings, as well as hear from pre-teens first-hand about their digital experiences. Although the interviews are not explicitly included in the article, they have informed our understanding of the digital practices of these particular groups of pre-teens. Consequently, the results of the online survey were analysed first and if any questions or concerns arose this was clarified through focus group data.

\section{Findings}

The data is organised by country and is presented in graphical form and divided into grades to enable easy comparison. In Australia, Grades 3 and 4 are typically children aged 7-10 years; Grades 5 and 6 are children aged 9-12. In Uruguay, Grade 4 is typically comprised of children 9-10 years old, while 
Grade 5 and 6 students are 10-12 years of age. We have also provided a written summary under each graph to clarify the data and highlight any points of interest.

\section{a. Online access}

The first three questions on the survey were designed to develop an overall picture of pre-teen's online practices. First, we asked participants which device/s they use to access the internet. We then asked how long they spend online and how much of this time is dedicated to learning.

\section{Australia}

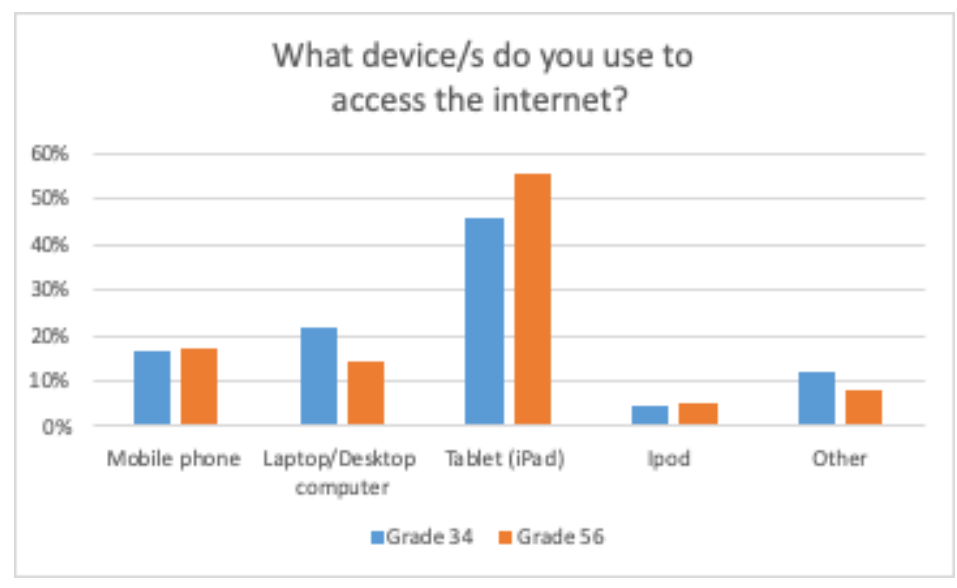

Figure 1 - Participant responses to the question, "What devices do you use to access the internet?" (Australia)

In Australia, the iPad was the most common device used to access the internet, which is perhaps not surprising given that at both schools all students from Grade 4-6 are expected to have one. However, closer inspection of the data reveals some interesting insights. If all students are expected to have an iPad, then it is significant that only $46 \%$ of Grade $3 / 4$ student and $55 \%$ of Grade $5 / 6$ students use it to go online. As many of the school based activities require the internet it appears students are actually not aware of the fact that they are online. This could be due to the fact that going online has become a rather seamless process and happens automatically in many schools and homes. The consequence of this is that many students are not aware of the fact that their digital practices resonate beyond the device and can be used in the digital economy. Mobile phones were the next most popular device for Grade 5/6 to access the internet, whereas the laptop/desktop computer was next for Grades 3/4. 


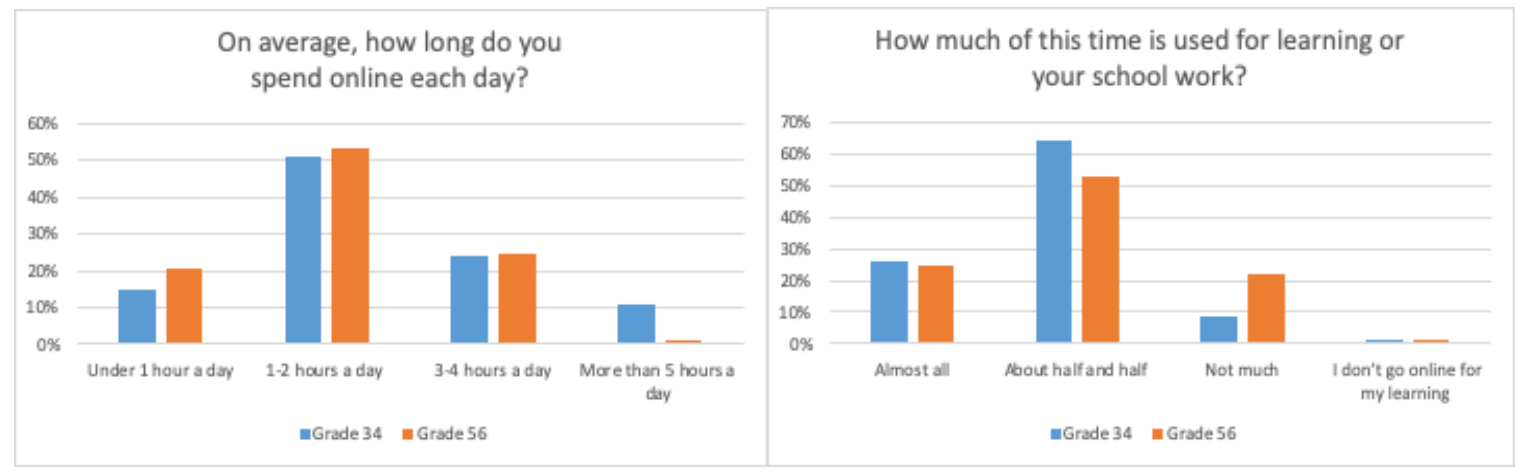

Figures 2 \& 3- Participant responses to the questions: "On average, how long do you spend online each day?" And "How much of this time is used for learning or your school work?" (Australia)

The majority of pre-teens spend 1-2 hours a day online; more specifically $51 \%$ of younger pre-teens and $53 \%$ of older pre-teens. However, the younger age group appears to spend longer online than the older pre-teens, with $35 \%$ of Grade $3 / 4$ students spending 3 or more hours a day online, compared with $26 \%$ of Grade $5 / 6$ students. While the majority of students share their time online equally between learning and leisure (64\% of younger and $53 \%$ of older), survey responses indicate that older pre-teens (aged 9-12) start using the internet for leisure (i.e. social networking and entertainment) with $22 \%$ of Grade $5 / 6$ students doing "not much" learning online, compared to only $8 \%$ of Grade $3 / 4$ students. Roughly a quarter of students in both age groups spend "almost all" their time online learning.

\section{Uruguay}

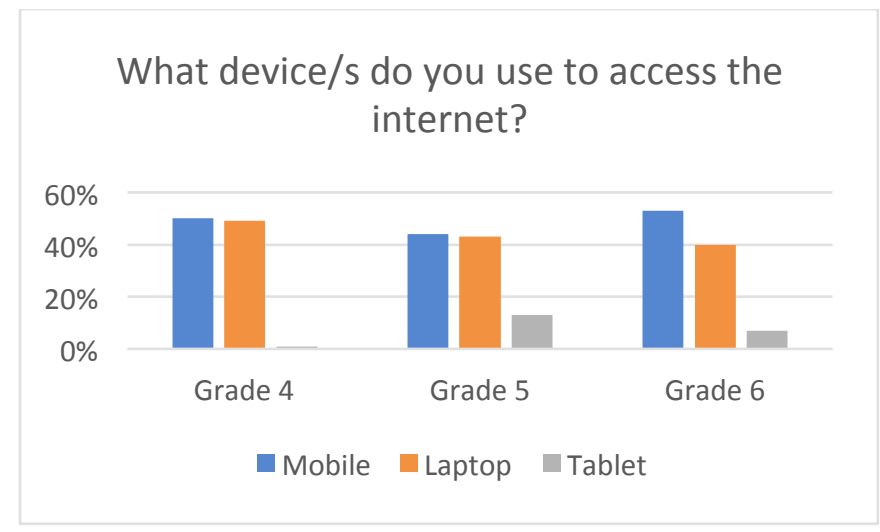

Figure 4 - Participant responses to the question, "What devices do you use to access the internet?" (Uruguay)

In the Uruguayan context, mobile phones were the most common device used by pre-teens to access the internet. Most children claimed they had their own device, while few were using a borrowed one from a family member. Following mobile phone usage, laptops and computers were the second device most used. Very few students used tablets across grades. Laptop use in the country is related to public science and technology policy. Since 2007, Uruguay, through Plan Ceibal, has distributed personal computers to both students and teachers, as well as provided internet connection to schools (Pérez Burger, Ferro, Baraibar, Pérez, Salamano, \& Pagés, 2009). 

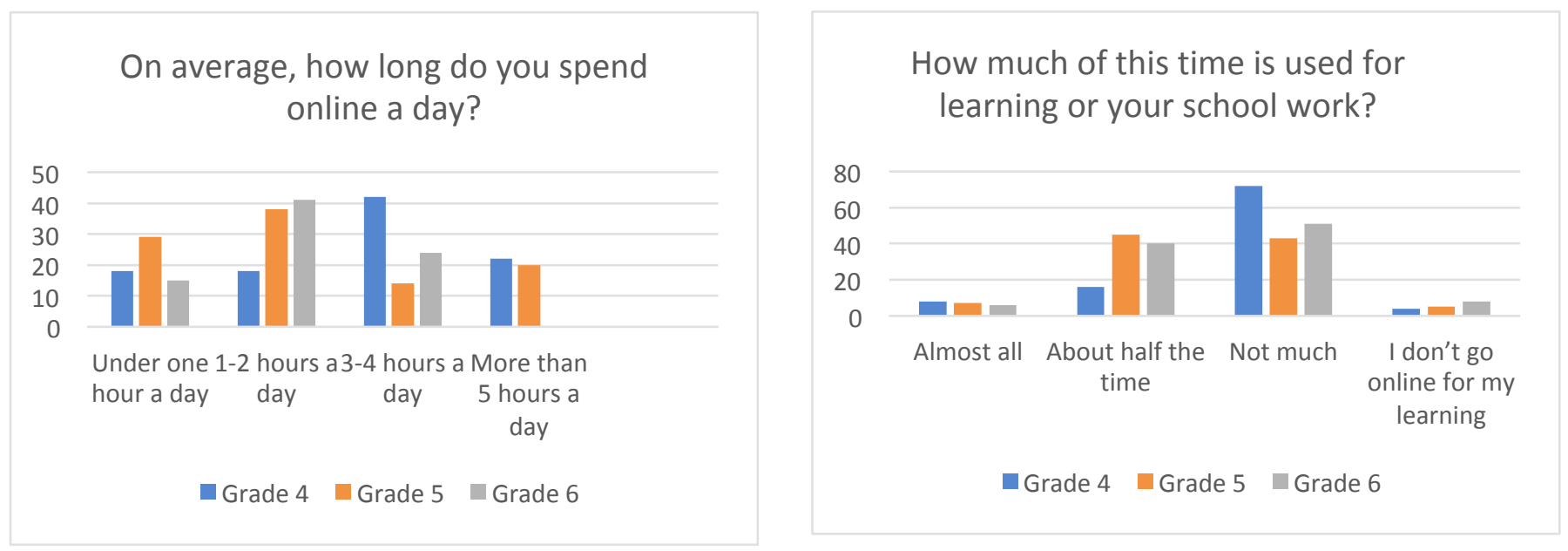

Figure 5 \& 6 - Participant responses to the questions: "On average, how long do you spend online each day?" And "How much of this time is used for learning or your school work?" (Uruguay)

Time spent online each day varied between grades and schools. Grade 4 students spend 3-4 hours a day, and $22 \%$ spend over 5 hours a day. Students in grades 5 and 6 showed different practices both in terms of their age and the school they were attending. It must be noted that students attending the extended time participating school spent less than 5-hours per day online, as opposed to their regular 4-hour school counterparts.

The survey showed that Uruguayan students are unlikely to use the internet to complete homework and other school-related tasks, with up to only $8 \%$ of students in each grade stating they spent "almost all of their time online" doing such work. On the contrary, students seem to spend time chatting with peers, sharing photographs and gaming online, with $4^{\text {th }}$ graders being the most likely to engage in unrelated school tasks.

\section{b. Social media}

The second group of were related to student's use of social media. First, we asked students to indicate whether they had a social media account and which platforms they were on. To develop a sense of the history of their social media practices, we then asked them to indicate the first social media platform they opened and how long they have had the account. Finally, we asked who they spoke to if they had any issues with social media. 


\section{Australia}

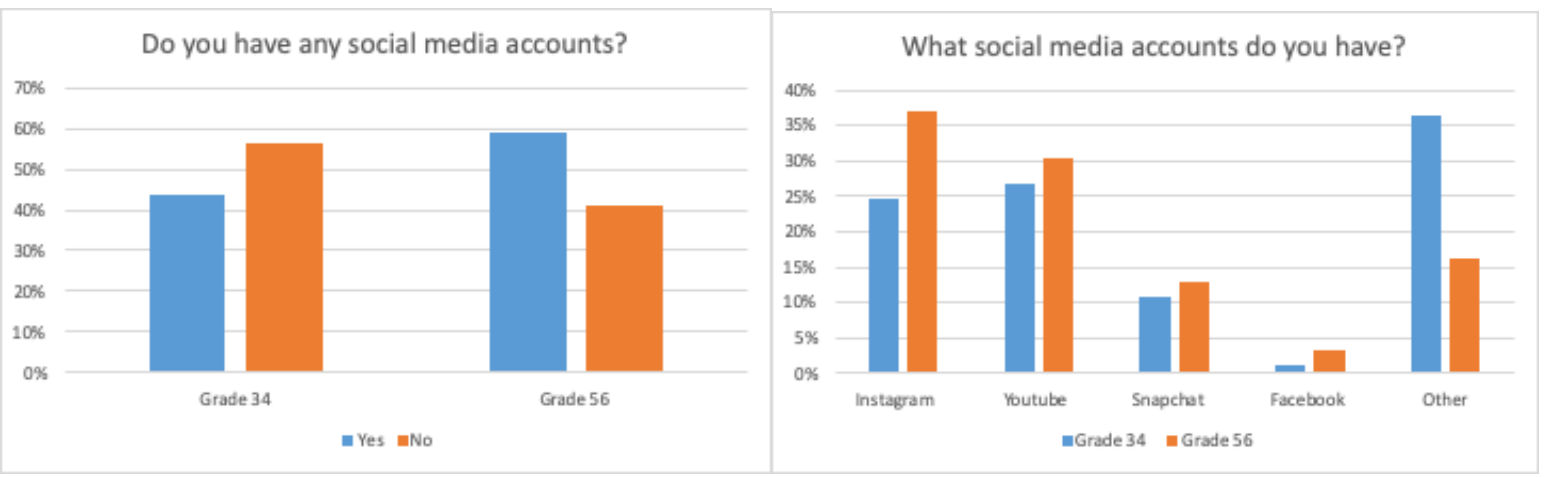

Figures $7 \& 8$ - Participant responses to the questions: "Do you have any social media accounts?" And "What social media accounts do you have?" (Australia)

The survey responses indicate that in Australia Grade 5 ( $9-10$ years) is a critical time for pre-teens to open a social media account. For example, in Grade 3/4 the majority (56\%) of students do not have a social media account. However, the Grade $5 / 6$ survey responses indicate that the majority (59\%) do have a social media account, suggesting that the end of Grade 4, beginning of Grade 5 is a key time for young people to begin social networking in Australia.

Of the students who have a social media account, Instagram and YouTube are clearly the most popular platforms. This highlights the importance of visual communication among pre-teens, as Instagram and YouTube are based around sharing images and videos. Snapchat is also largely visual and the third most popular platform. Another interesting aspect to the survey responses was the great variety of other niche social media sites pre-teens are on. For example, significant numbers of participants were socialising on apps associated with Roblox (17), Minecraft (7) and Fortnite (2), and many were on Messages (14) - an app automatically downloaded onto Apple devices. Small numbers were on Tik Tok (3), Steam (1), Musical.ly (1), Facetime (1) and Club Penguin (1).

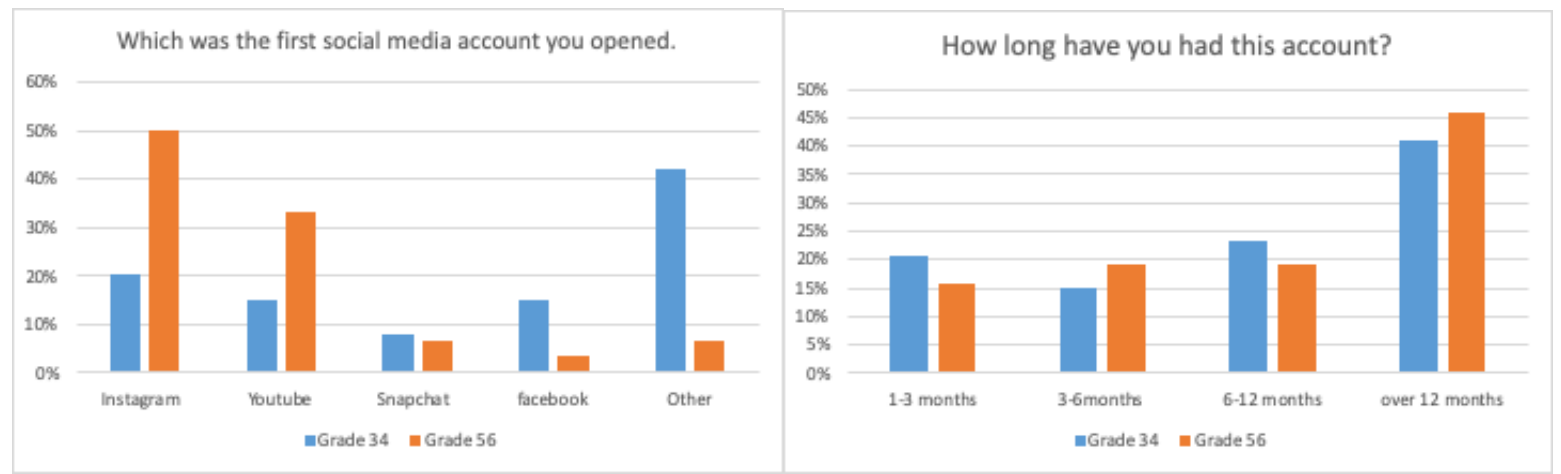

Figures 9 \& 10 - Participant responses to the questions "Which was the first social media account you opened?" And "How long have you had this account?" (Australia)

Survey data indicates that Instagram is the most popular platform for Australian pre-teens to start on, with $50 \%$ of older pre-teens and $20 \%$ of younger pre-teens signing up to this platform. YouTube is also a popular stepping stone into social media with $33 \%$ of older pre-teens and $15 \%$ of young pre- 
teens indicating it was the first social media platform they signed up to. Surprisingly, fewer younger pre-teens indicated that they had used a mainstream platform, such as Instagram or Snapchat, to open their first account. Instead, over $40 \%$ of younger pre-teens first opened a social media account on a collection of "Other" platforms, such as Roblox, Messages, Minecraft and TikTok. This indicates that the "pathways" into social media are expanding, with many educational and/or commercial companies including a social media app for children to download as part of their engagement.

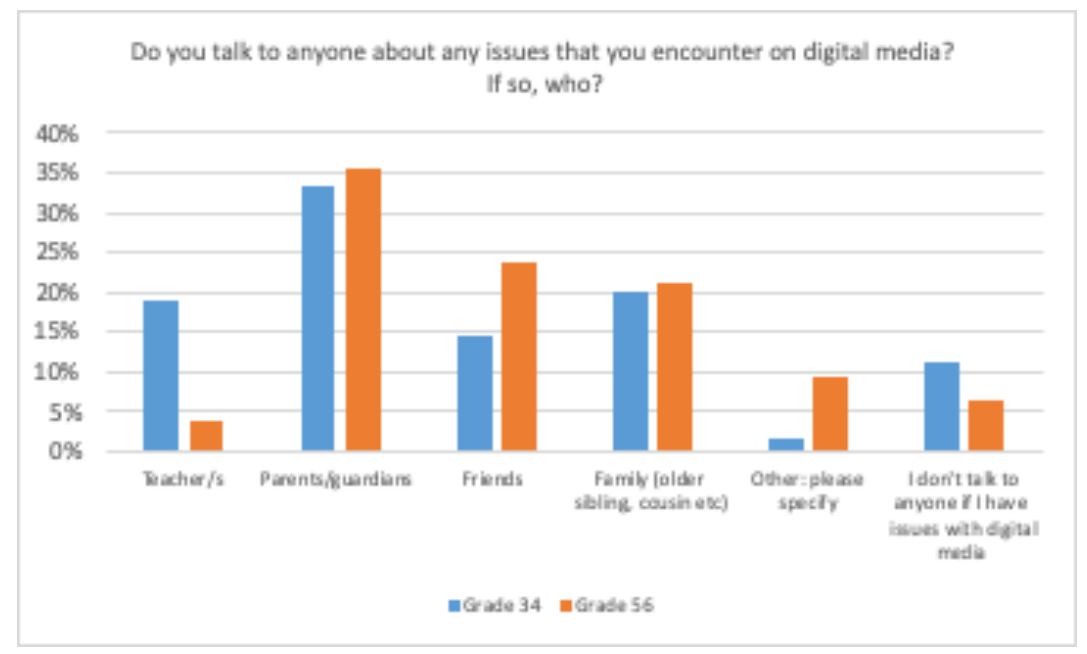

Figure 11- Participant responses to the question responses to the question, "Do you talk to anyone about any issues that you encounter on digital media? If so, who?" (Australia)

We asked students to indicate who they would approach if they had issues with social media. For both older and younger pre-teens, parents/guardians were the most popular, followed by friends and family. Small numbers of students across all cohorts indicated they did not talk to anyone when they have issues with social media. Older pre-teens were less willing to talk to teachers about issues they are having when compared to younger pre-teens. Other responses for younger pre-teens indicate they either do not have any issues with social media or do not have social media - the latter being most likely.

\section{Uruguay}
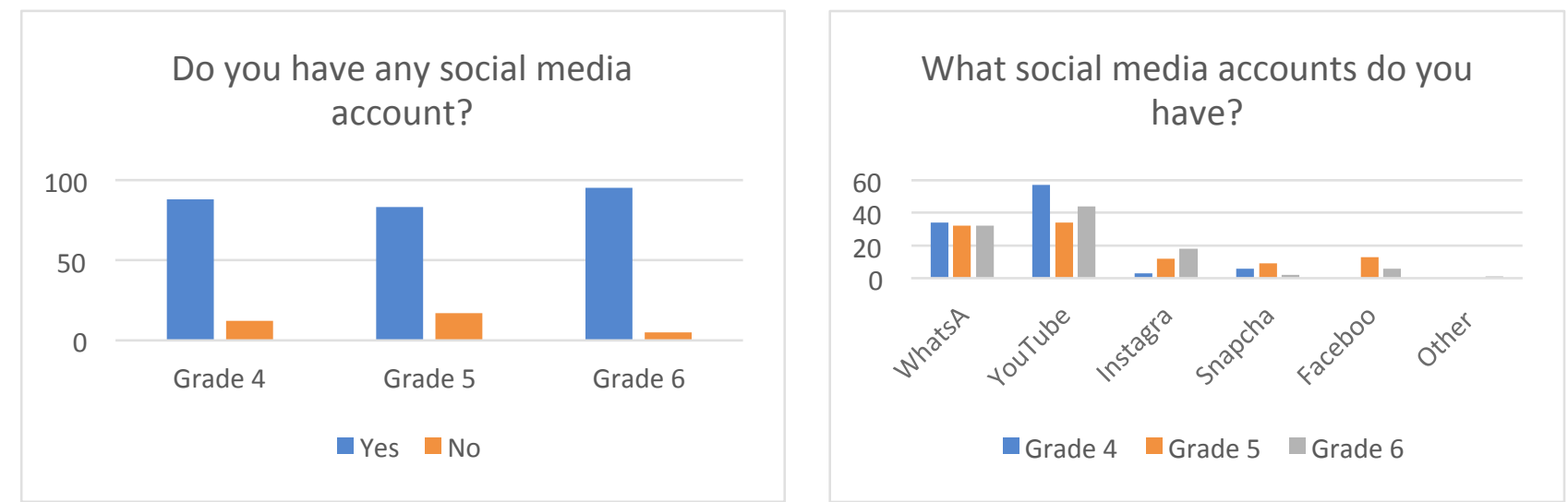

Figure 12 \& 13 - Participant responses to the questions: "Do you have any social media accounts?" And "What social media accounts do you have?" (Uruguay) 
The survey responses indicate that the majority of students have already opened a social media account. Almost all Grade 6 students, $96 \%$, as well as $93 \%$ for each school have an account.

Of the students who have a social media account, WhatsApp and YouTube are the most used platforms both for entertainment and interacting with peers. The data shows that platforms such as Facebook and Instagram are the least popular among Uruguayan pre-teens.

An interesting characteristic of the data collected in these surveys indicate that Australian and Uruguayan teens have conceptualized social media platforms differently. With the increasing popularity of WhatsApp, Uruguayan teens are remixing the ways in which they use this chat app, as a social media one, by creating groups where they share pictures, videos, audio recordings and other snapshots of their daily lives. The content they share on WhatsApp is similar to the one they would share on other social media networks.

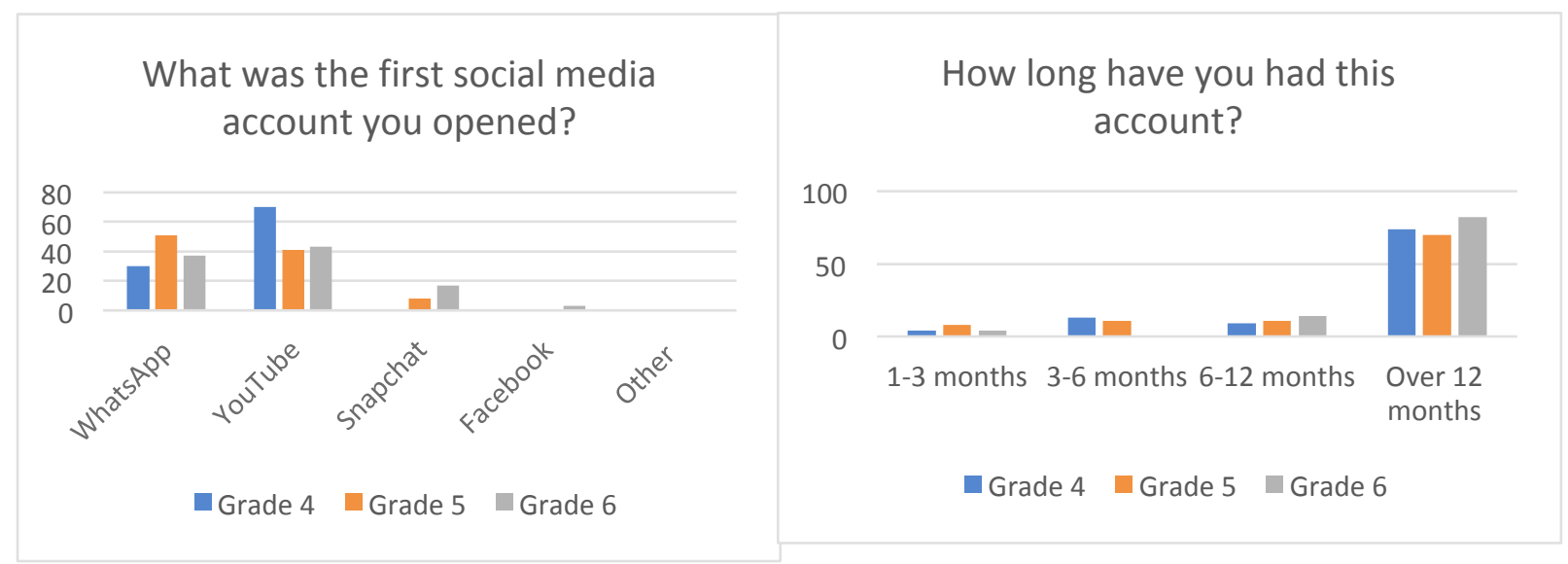

Figures 14 \& 15 - Participant responses to the questions "Which was the first social media account you opened?" And "How long have you had this account?" (Uruguay)

Students show loyal behavior in terms of the platforms they use and the account they first opened, with $80 \%-100 \%$ stating WhatsApp and YouTube are the first accounts they opened. Regarding time, the majority of students in each grade report they have been using their social media accounts for over 12 months at the time of the survey. 


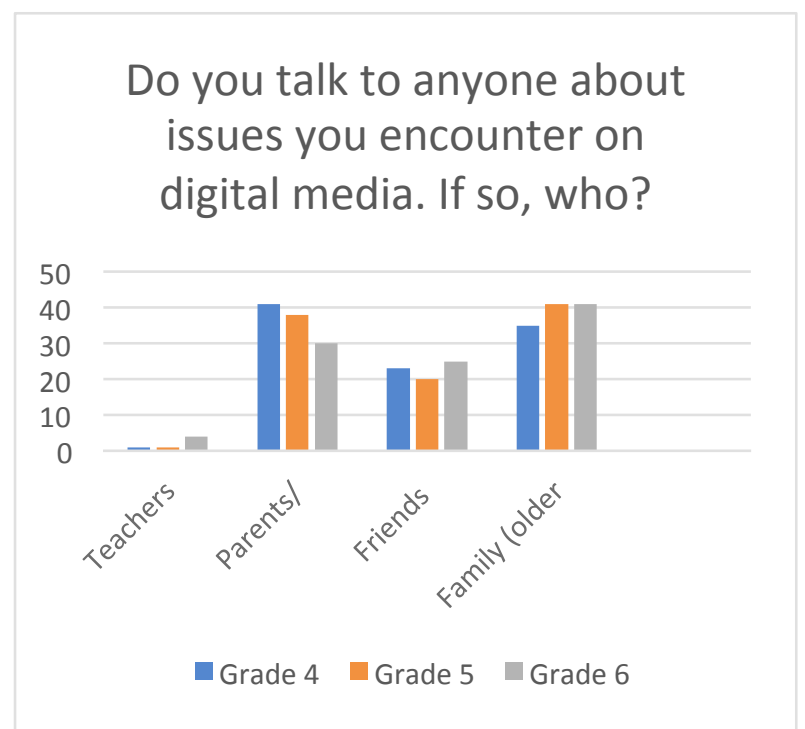

Figure 16 - Student responses to the question, "Do you talk to anyone about any issues that you encounter on digital media? If so, who?" (Uruguay)

When asked about who they would approach if they had issues with social media, students across grades indicated that they would speak with a parent/guardian or another family member, followed closely by friends, which does not increase significantly in older grades. Very few students indicated that they would approach a teacher. None of the students in the study claimed they would not talk to anyone if an issue on social media would arise. Interestingly, in Uruguay, students indicated that mobile phones are the most popular way to access the internet, followed by laptops. It must be noted that in Uruguay, students in primary school receive laptops for learning purposes. If students use their non-school device (mobile phones) to access social media, it would be expected that teachers would not be the person they approach when they encounter an issue on social media.

\section{Discussion}

Our findings highlight just how developed pre-teens' digital practices are. Not only are they making use of digital devices in the home, but they are also encouraged to use mobile devices, laptops, and tablets at school. For example, in Australia, all students in participating schools are expected to have an iPad from the age of nine. In Uruguay, students in public schools receive a device, either a laptop or a tablet, in Pre-Kindergarten (aged 4-5 years). Our findings highlight that many pre-teens are often unaware when they are online, which has implications for the protection and management of their privacy.

While digital devices are often introduced for educational purposes, the findings of our survey indicate that pre-teens quickly start to use these devices for leisure. While this is not a problem per se, it can make it difficult for parents and teachers to know what pre-teens are doing and how to support them, especially as many of the apps and social media platforms used by the pre-teens in our study are discursively constructed as "educational" or automatically installed on school based devices. By the age of nine, many pre-teens already have at least one social media account, many of which are on mainstream platforms that have a minimum age requirement of 13 years. Interestingly, in Australia 
younger pre-teens were not initiated into social media via one of the mainstream platforms, and instead started social networking via a variety of more niche platforms associated with other digital practices. While it is encouraging that pre-teens are exploring a range of different platforms, it also expands the issues they may encounter through use. We now identify these challenges and investigate what this means for digital learning.

\section{a. Pre-teens require sophisticated digital literacies to negotiate their online identities}

Our findings show that pre-teens are being initiated into social media at younger and younger ages. Like similar research (Marsh, 2014; Weber \& Mitchell, 2008), our data has shown how digital media enable pre-teens to experiment with and construct their identity. Previous work has shown that social media can encourage pre-teens to challenge different aspects of their persona (Burley, 2010), while others have found that pre-teens' social media practices tend to reflect cultural norms and values (Abiala \& Hernwall, 2013). Influencing their practices are the understandings and assumptions that pre-teens and their peers have of particular social media platforms. Indeed, digital identities are shaped by the architecture and interface of the platform, so that websites are both a "constructive as well as a projective medium" (Turkle, 1995, p.26).

This is a complex process for any user to navigate, as representations of identity on digital media are compared, adjusted, or defended across a variety of technical and social realities. This is potentially more difficult for pre-teens as they are just beginning to work out their social identities. Furthermore, given current trends it seems likely that children will continue to open social media accounts at younger and younger ages, especially as major platforms like Facebook are now marketing services for this demographic. Potentially every piece of information shared - from photos, nicknames, email addresses and comments - can be used to make inferences about an individual's identity (Marwick, 2013). Given the permanence of digital data, these inferences will not only be made by friends and acquaintances, but also those who can affect young people's futures, such as employers and colleagues. As such, the negotiation of digital identities has both short and long term implications for pre-teens.

\section{b. Managing privacy in networked contexts}

While using social media gives young people access to information, education and social opportunities across a variety of contexts, it inevitably involves disclosing and sharing personal information. In order to create a profile on a social media platform, users are encouraged to disclose personal details, such as their name, town and school. Indeed, sharing personal information on social media is integral to the maintenance of social relationships and key to developing intimacy with peers. Livingstone's (2008) work with British teenagers showed that it is not so much the quantity of personal information disclosed on social media that is significant, but with whom that information is shared. As such, knowing what to share on social media and who to share with requires technological and social literacies. Several studies have shown that just like adults, children and young people also value privacy and take measures to protect their privacy online (Marwick \& boyd 2014; Tufecki, 2008; Davis \& James, 2013). Despite this, privacy measures employed by pre-teens have been found to be "haphazardly employed" with many displaying "uncertainty or ignorance" about their settings (Davis \& James, 2013, p.23).

The pre-teens in our study are operating across a variety of platforms and websites, meaning it is potentially more difficult for them to stay abreast of the privacy settings for each. Some of these (i.e. Messages) are encouraged by the school itself, opening the "gateway" to social media use. In light of 
this, and the fact that many pre-teens are both unaware of being online and already using a whole host of platforms, a key priority for digital learning should be managing and protecting privacy in networked contexts.

\section{c. Understanding the implications of personal data generation}

A growing area of concern is the reuse and repurposing of personal data that results from social media use. On social media, the platform owners have the power to aggregate and distribute the information that users share with the site, meaning that users, in a sense, share control of their personal data. Indeed, it is paradoxical that at the same time young people experience the freedom of online communication, they compromise control over their personal data. Once processed by particular algorithms, personal data can produce meanings that define children, opening up particular pathways of becoming. Further, personal data are not only generated through use of social media, but are involuntarily generated through children's everyday activities, which could lead to specific implications for this generation of children (cf. Lupton \& Williamson, 2017). This was evident in our data, which indicated that pre-teens were not often aware when they were online, meaning they were likely generating personal data without knowing it. In some cases, these data are used without people's knowledge or consent, sometimes illegally by hackers and cybercriminals (Lupton, 2019). Recent research has highlighted the need to balance the opportunities and benefits of connectivity with children's data protection and basic rights (Swist \& Collin, 2017; Livingstone \& Third, 2017).

Many of the pre-teens in our study were using platforms (Instagram, Snapchat, Facebook) that have a minimum age of 13 years as this is the age at which technology companies can collect personal data of users without parental consent, according to the USA's Children's Online Privacy Protection Act (1998). However, YouTube, the most popular social media platform used by participants in both Australia and Uruguay, has a minimum age of 18 years, unless the child has signed up with parent's knowledge and consent. This becomes a legal loophole for platform operators as they often market to younger demographics but then are not held responsible for the implications as children under 13 years are not supposed to use the service.

\section{Concluding remarks: What does this mean for school based digital learning?}

In this article, we examined the digital practices of pre-teens in Australia and Uruguay. Although there were differences between the two groups, many of the challenges that these pre-teens face through their use are the same. Our findings highlight that while there is a need for students to be cybersafe, there are several other issues that children are facing. Within this context, schools and teachers should play a key role in explicitly helping students to unpack and understand the wide-range of information they receive, as well as guiding them in the choices they have to make (Cardozo-Gaibisso, Pangrazio, Azpiroz, 2020). However, in the participating schools teaching and learning practices that focus on developing social media literacies are scarce. There are multiple recommendations related to classroom instruction that emerge from the data gathered and analyzed in this study. However, these cannot be comprehensive unless they take into account the current state of teacher education and teacher professional learning contextually. First, by exploring how teachers, especially those working with this age group, are being prepared to address digital literacy, and how their lived experiences and previous knowledge influence their classroom practices.

While there is literature (e.g. Day \& Sachs, 2004; Garet, Porter, Desimone, Birman, \& Yoon, 2001) that shows that teacher participation is key to produce shifts in teachers' understandings, there is still 
a tendency to provide teachers with top-down approaches that show them what to do, instead of enacting a dialogical approach. This tendency has proven, of course, ineffective to produce sustained and effective teacher pedagogical change (Gross, 2010; Konza \& Michael, 2010). As pre-teens tend to access social media at a younger age each year, not only do we need to dismantle the cybersafety rhetoric in favor of a critical approach to digital and particularly social media literacies, but we also need to put teachers back in the picture, making sure that they can make informed decisions in the classroom.

Most significantly, our findings highlight the need for school based digital learning to move beyond the protectionist discourse of cybersafety in order to address the challenges and opportunities pre-teens face through their everyday use of digital media. In our work with Uruguayan and Australian students we observed that, despite the difference in contexts and languages, the use of social media does not imply knowledge of their scope and risks. To make the most of the opportunities that digital media offer, children and young people require guidance and support to develop critical skills and dispositions (Isin \& Ruppert, 2015). In particular, our research has highlighted the need to support the development of their social media literacies, including: representing digital identities across contexts; understanding the implications of personal data generation; and managing and protecting privacy in networked contexts.

In contrast to the approaches that try to promote cybersafety of preteens by limiting their access to social networks, the concept of digital literacy is much more complex, both in its theoretical formulation and in its practical dimension. It involves the articulation of a series of mechanisms inside and outside of schools, and requires the participation of several social actors (teachers, principals, families, among others). Building a digital literacy framework implies, therefore, critical reflexivity regarding the implications of creating data profiles and regarding the recirculation of that data (Mathieu, 2016). Applying this critical approach implies developing understanding of the quantity and quality of data that they share on social networks, and how that data is being processed and utilized.

\section{References}

Abiala, K., \& Hernwall, P. (2013). Tweens negotiating identity online- Swedish girls' and boys' reflections on online experiences. Journal of Youth Studies, 16(8), 951-969.

Berger, K. S. (2014). The Developing Person Through the Life Span (9th ed.). London: Worth Publishers.

Brito, P. Q. (2012). Tweens' characterization of digital technologies. Computers \& Education, 59, 580593.

Burley, D. (2010). Penguin life: A case study of one tweens' experiences inside Club Penguin. Journal of Virtual Worlds, 3(2), 1-12.

Cardozo-Gaibisso, L., Pangrazio, L., Azpiroz, M. (2020). La Preadolescencia Datificada. Pistas y lecciones aprendidas en una intervención en Uruguay y Australia. In Educar y aprender en la era digital: Una mirada desde la investigación (pp. 127-149). Uruguay: CmIpresos.

Davis, K., \& James, C. (2013). Tweens' conceptions of privacy online: Implications for educators. Learning, Media and Technology, 38(1), 4-25.

De Souza, Z., \& Dick, G. N. (2008). Information disclosure on MySpace - the what, the why and the implications. Pastoral Care in Education, 26(3), 143-157.

Denham, P. (1993). Nine to fourteen-year-old children's conception of computers using drawings. Behaviour and Information Technology, 12(346-358).

Emejulu, A., \& McGregor, C. (2019). Towards a radical digital citizenship in digital education. Critical Studies in Education, 60(1), 131-147.

Hope, A. (2013). The politics of online risk and the discursive construction of e-safety. In K. Facer \& N. 
Selwyn (Eds.), The Politics of Education and Technology: Conflicts, controversies and connections (pp. 83-98). London: Palgrave/Macmillan.

Leathers, H., Summers, P., and Desollar, A. (2013) Toddlers on Technology: A Parents' Guide. Illinois: AuthorHouse.

Livingstone, S. (2008). Taking risky opportunities in youthful content creation: Teenager's use of social networking sites for intimacy, privacy and self-expression. New Media \& Society, 10(3), 393-411.

Livingstone, S. (2009). Children and the Internet: Great Expectations, Challenging Realities. Cambridge, UK: Polity Press.

Livingstone, S., \& Third, A. (2017). Children and young people's rights in the digital age: An emerging agenda. New Media \& Society, 19(5), 657-670.

Livingstone, S., \& Helsper, E. (2010). Balancing opportunities and risks in teenagers' use of the internet: The role of online skills and self-efficacy. New Media \& Society, 12(2), 309-329.

Lupton, D. (2019). Data Selves. London: Polity

Lupton, D., \& Williamson, B. (2017). The datafied child: The dataveillance of children and implications for their rights. New Media \& Society, 19(5), 780-794.

Marsh, J. (2014). Purposes for literacy in children's use of the online virtual world Club Penguin. Journal of Research in Reading, 37(2), 179-195.

Marwick, A. (2013). Online identity. In J. A. Hartley, J. Burgess, \& A. Bruns (Eds.), A Companion to New Media Dynamics. Oxford, UK: Wiley-Blackwell.

Marwick, A., \& boyd, d. (2014). Networked privacy: How teenagers negotiate context in social media. New Media \& Society, 16(7), 1051-1067.

Marwick, A., Fontaine, C., \& boyd, d. (2017). "Nobody sees it, nobody gets mad": Social media, privacy and personal responsibility among low-SES youth. Social Media + Society, April June(Advanced online edition), 1-14.

Miller, D. et al., (2016). How the World Changed Social Media. London: UCL Press.

Pangrazio, L. (2019). Young People's Literacies in the Digital Age: Continuities, Conflicts and Contradictions Abingdon, UK: Routledge.

Roddel, V. (2006). Internet Safety Parents' Guide. Morrisville, NC: LuLu Press.

Selwyn, N. (2004). Reconsidering Political and Popular Understandings of the Digital Divide. New Media \& Society, 6(3), 341-362. https://doi.org/10.1177/1461444804042519

Shin, W., Huh, J., \& Faber, R. J. (2012). Tweens' online privacy risks and the role of parental mediation. Journal of Broadcasting \& Electronic Media, 56(4), 632-649.

Swist, T., \& Collin, P. (2017). Platforms, data and children's rights: Introducing a 'networked capability approach'. New Media \& Society, 19(5), 671-685.

Third, A., Forrest-Lawrence, P., \& Collier, A. (2014). Addressing the cyber safety challenge: From risk to resilience. Retrieved from http://apo.org.au/files/Resource/telstra_addressing-cyber-safetychallenge_2014_2014.pdf

Tufecki, Z. (2008). Can you see me now? Audience and disclosure regulation in online social network sites. Bulletin of Science, Technology \& Society, 28(1), 20-36.

Turkle, S. (1995). Life on the Screen: Identity in the Age of the Internet. New York Touchstone.

Weber, S., \& Mitchell, C. (2008). Imaging, keyboarding, and posting identities: Young people and new media technologies. In D. Buckingham (Ed.), Youth, Identity and Digital Media. Cambridge, MA: The MIT Press.

Yan, Z. (2005). Age differences in children's understanding of the complexity of the internet. Applied Developmental Psychology, 26, 385-396.

Young, S. (2019). Social media being used by a growing number of children under 11 despite age limits. Independent. Retrieved from https://www.independent.co.uk/life-style/children-socialmedia-use-age-limit-facebook-instagram-profiles-a8756096.html 